\title{
NATIONWIDE MONITORING OF GEOHAZARDS IN GREAT BRITAIN WITH INSAR: FEASIBILITY MAPPING BASED ON ERS-1/2 AND ENVISAT IMAGERY
}

\author{
Cigna Francesca, Bateson Luke, Jordan Colm, Dashwood Claire \\ British Geological Survey, Nicker Hill, Keyworth, Nottingham NG12 5GG, United Kingdom. \\ E-mail: $\underline{\text { ccigna@bgs.ac.uk }}$
}

\begin{abstract}
We model terrain visibility and topographic distortions to the ERS-1/2 SAR and ENVISAT ASAR IS2 satellite acquisition modes in Great Britain using the $5 \mathrm{~m}$ NEXTMap DTM. Predictions of Persistent Scatterers (PS) densities identifiable over the landmass are drawn using the CORINE Land Cover 2006 dataset which is calibrated based on 6 PS datasets available for various areas of the UK. InSAR feasibility to monitor ground motions is discussed through the example of the Manchester area, with particular regard to landslide deposits in the Peak District.
\end{abstract}

Index Terms - SAR interferometry, geohazards, Persistent Scatterers, topographic distortions, land cover calibration

\section{INTRODUCTION}

Starting in the late 1990s, an increasing number of applications of Synthetic Aperture Radar Interferometry (InSAR) over (sub-)urban areas in Europe has showed high potential for these technologies to support mapping and monitoring of ground motions associated with a wide range of geohazards, from the local to the regional scale, and with up to millimeter precision [1-2].

Especially in recent years, many national initiatives such as the projects SLAM [3], DO-SMS [4], and international projects such as ESA Terrafirma [5], the EC FP7 SAFER [6] and DORIS [7], are exploiting single-pair InSAR and multiinterferometric techniques such as Persistent Scatterer Interferometry (PSI) and Small-Baseline (SBAS) approaches for landslide mapping and operational support to regional and national bodies and local authorities in charge of hazard and risk management and landuse planning. Updating landslide inventory maps, monitoring and characterizing unstable slopes, increasing understand of landslide dynamics and contributing to mitigation activities, are examples of inputs that InSAR-derived ground motion data can provide to support landslide hazard and risk analysis [3-9].

Building upon the achievements of the radar remote sensing landslide community over the last two decades, the
British Geological Survey (BGS) has been evaluating the potential of InSAR techniques for landslide research and applications for Great Britain, in the framework of a research project funded by the Natural Environment Research Council (NERC) [10].

In this paper, we present the results from the first stage of the project, which focussed on mapping the feasibility of InSAR and PSI techniques over Great Britain by considering SAR imagery limitations due to topographic distortions and land cover effects. Results of our feasibility mapping are discussed for the area of Manchester and the Peak District in central/northern England. Conclusions and ways forward are proposed for the use of this approach over the entire landmass.

\section{MAPPING TOPOGRAPHIC DISTORTIONS}

Visibility of the terrain to the satellite sensor depends on the orientation of the land surface with respect to the acquisition geometry (i.e. the orientation of the satellite Line-Of-Sight, LOS), and can vary within different portions of the same scene, depending on local topography. The use of suitable acquisition geometries for the investigated area is thereby essential for any InSAR analysis to ensure the target area is visible to the employed sensor mode.

To define the orientation of the ascending and descending LOS of ERS-1/2 SAR and ENVISAT Advanced SAR (ASAR) Image Swath 2 (IS2), we employed a $23^{\circ}$ look angle with respect to the vertical direction, and $\pm 14^{\circ}$ track angle (orbit inclination with respect to the N-S direction). Local terrain orientation was assessed by employing the $5 \mathrm{~m}$ airborne InSAR NEXTMap Digital Terrain Model (DTM) produced by Intermap, and its $10 \mathrm{~m}$ and $50 \mathrm{~m}$ derivatives.

Geometrical distortions (i.e. foreshortening, layover and shadow) were identified by combining the approaches by Kropatsch \& Strobl [11] to identify active and passive layover and shadow, and Notti et al. [12] to map the topographic R-index. The latter represents an indication of the ratio between the pixel size in ground and slant range geometry, and allows identification of areas of good terrain visibility, as well as foreshortening and active layover. Its values range between -1 and +1 , and are higher than +0.3 
over regions of good to very good visibility (i.e. slopes facing away from the SAR sensor), and between 0 and +0.3 for areas affected by foreshortening (i.e. slopes facing the sensor and with steepness lower than the look angle). Rindex values lower than 0 indicate active layover, hence slopes facing the sensor and steeper than $\theta$, thus producing layover onto other areas.

Figure 1 shows the resulting InSAR topographic visibility map in the ERS-1/2 and ENVISAT IS2 ascending mode for the area of east Manchester and the Peak District in central/northern England. Active and passive layover and shadow masks are overlapped onto the R-index map, and identify areas where the above acquisition mode and geometry are not suitable to investigate land motions with SAR imagery acquired with that LOS.
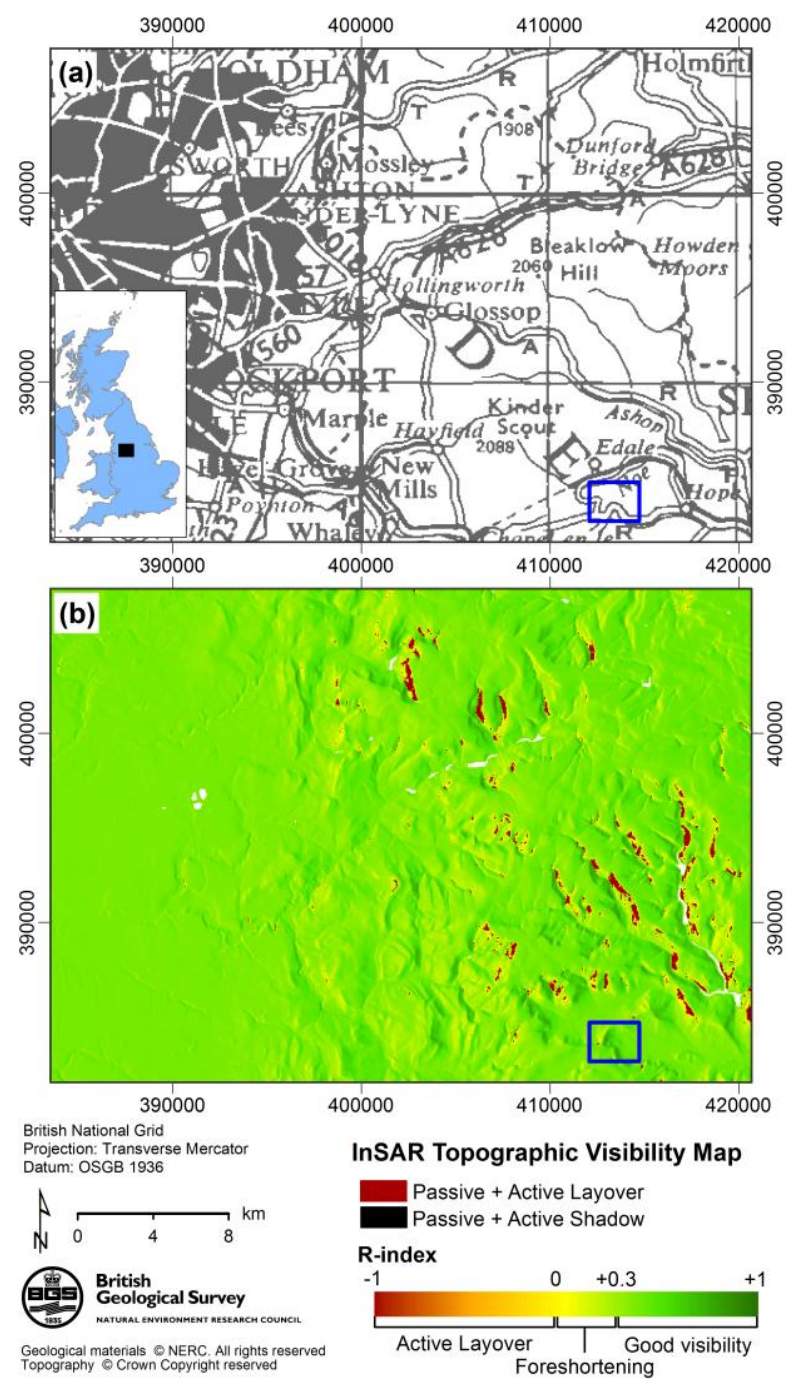

Figure 1: (a) OS 1:625,000 topographic map and (b) InSAR topographic visibility map based on 50m NEXTMap DTM for the area of Manchester and the Peak District, UK. The latter shows modeled topographic distortions and terrain visibility to the ERS$1 / 2$ and ENVISAT LOS geometry in ascending mode $\left(23^{\circ}\right.$ look angle, $14^{\circ}$ track angle). The blue rectangles indicate the location of the Mam Tor landslide area represented in Figure 3.

\section{CALIBRATING LAND COVER FEASIBILITY}

Persistent Scatterers relate to surface objects with a high temporal coherence that can be identified throughout the radar data stack. Such objects are associated with land cover; typically urban areas display a higher PS density than rural areas.

Our feasibility study aims to provide a quantitative assessment of the likelihood of obtaining PS points for a given area/land use. It is important to not only consider the possibility of obtaining points but also the expected density of resulting PS points for the area under consideration. Since PS density is related to land cover it was necessary to derive the average PS density expected for each land use category in the UK.

Relationships were sought between the EEA CORINE 2006 land cover map polygons [13] and six PSI datasets for various areas of the UK (Table 1).

\begin{tabular}{|l|l|l|l|l|}
\hline Town & Satellite & Mode & Dates & $\begin{array}{l}\text { No. of } \\
\text { scenes }\end{array}$ \\
\hline London & ERS-1/2 & Ascending & $\begin{array}{l}19 / 06 / 1992- \\
31 / 07 / 2000\end{array}$ & 27 \\
\hline London & ENVISAT & Descending & $\begin{array}{l}13 / 12 / 2002- \\
17 / 09 / 2010\end{array}$ & 45 \\
\hline Bristol/Bath & ERS \& & Descending & $\begin{array}{l}11 / 05 / 1992- \\
27 / 01 / 2005\end{array}$ & 75 \\
\hline $\begin{array}{l}\text { Stoke-on- } \\
\text { Trent }\end{array}$ & ERS-1/2 & Descending & $\begin{array}{l}11 / 05 / 1992- \\
27 / 02 / 2003\end{array}$ & 70 \\
\hline $\begin{array}{l}\text { Newcastle } \\
\text { and Durham }\end{array}$ & ERS-1/2 & Descending & $\begin{array}{l}19 / 04 / 1995- \\
14 / 12 / 2000\end{array}$ & 48 \\
\hline $\begin{array}{l}\text { Newcastle } \\
\text { and Durham }\end{array}$ & ENVISAT & Descending & $\begin{array}{l}03 / 12 / 2002- \\
07 / 10 / 2008\end{array}$ & 21 \\
\hline
\end{tabular}

Table 1: ERS and ENVISAT PSI datasets used to derive expected density for a given CORINE land cover class.

For each CORINE land cover polygon the number of co-incident PS points was extracted for each of the six PS datasets shown in Table 1. Following calculation of polygon areas, the average density (points per $\mathrm{km}^{2}$ ), maximum density and standard deviation were derived for each land cover class. The derived average densities were then ranked into nine classes with a rank of 1 corresponding to the highest density and 9 to areas with no PS points. The ranking allows for the future integration of results from different sensors which would be expected to provide a significantly different PS density.

Calibration of the CORINE Land Cover map (Figure 2) by the derived average densities and rankings allows for quick identification of the expected PS density for an area.

\section{DISCUSSION}

The topographic feasibility maps for the ERS-1/2 and ENVISAT ascending and descending modes show that topography is not the major limitation over most of Great 
Britain. Generally, the identified areas of layover and shadow for each satellite mode cover only small portions of the imaged areas (e.g., about $2 \%$ of the Manchester and Peak District area in Figure 1b). The mutual use of both ascending and descending image stacks can, evidently, compensate and complement the coverage of the terrain visible to the SAR sensor, by guaranteeing good visibility of E-, NE- and SE-facing slopes by using the ascending geometry, and $\mathrm{W}-, \mathrm{SW}$ - and $\mathrm{NW}$-facing slopes by using the descending mode.

Figure 3c-d shows the visibility of some areas of landslide deposits mapped in the BGS Digital Geological Map of Great Britain (DiGMapGB) at 1:50,000 scale and the National Landslide Database (NLD) in the area of Mam Tor, Derbyshire. While the two deposits on the NW-facing slope are visible to both ascending and descending LOS (with the exception of areas close to the scarps where layover is expected in the SAR ascending mode), the deposit on the SE-facing slope is characterized by layover over a $\sim 100 \mathrm{~m}^{2}$ area in the descending mode, thus indicating that this mode would not be suitable for a SAR-based study over this unstable slope.

Results from the CORINE data calibration confirm that land cover exerts significant control on the potential of PSI technologies over Great Britain. Whilst urban areas, industrial/commercial/port units, bare rocks and road/rail networks clearly have high likelihood to result in high densities of PS (up to several hundred per $\mathrm{km}^{2}$ with the PSI approach), densely vegetated areas, marshes and water bodies are characterized by low to null likelihoods.

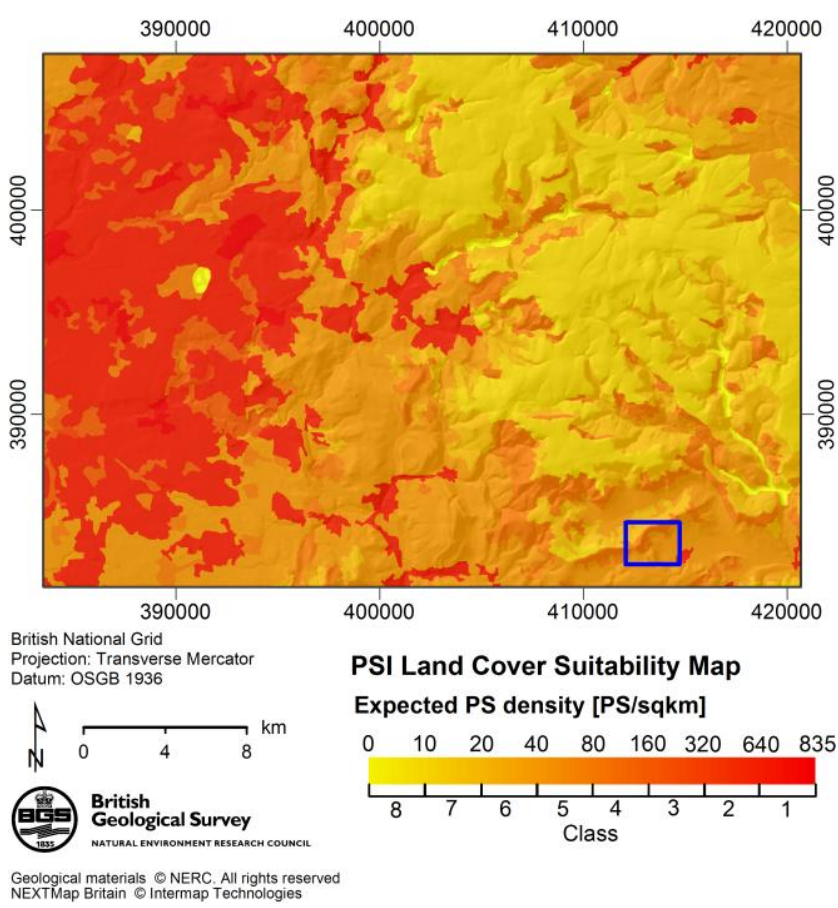

Figure 2: Calibrated CORINE Land Cover 2006 showing predicted PS densities for the different land cover types and classes in the area of Manchester and the Peak District in the UK.
By assuming the use of a PSI approach with ERS-1/2 or ENVISAT data over the area of Manchester in Figure 2 $\left(\sim 1,100 \mathrm{~km}^{2}\right)$, the calibrated CORINE Land Cover map shows highest predicted densities of radar targets (i.e. 400 to $800 \mathrm{PS} / \mathrm{km}^{2}$ ) over the dense urban areas of Manchester to the west, and minimum densities (i.e. 5-20 PS/ $/ \mathrm{km}^{2}$ ) over peat bogs, moors and heathland to the east of the area. The total number of expected targets over the entire area of Figure 2 might exceed 142,000 PS.

For the area of Mam Tor, the land cover feasibility map shows predicted target densities of $\sim 20 \mathrm{PS} / \mathrm{km}^{2}$ over moors and heathland (where the two landslide deposits on NWfacing slopes are mapped), $\sim 30 \mathrm{PS} / \mathrm{km}^{2}$ over pastures (southeastern and north-western sectors) and $\sim 60 \mathrm{PS} / \mathrm{km}^{2}$ over the natural grasslands, at the highest elevations (Figure 3e). Use of higher resolution data (e.g. TerraSAR-X or COSMOSkyMed) or advanced processing techniques [14] might increase these densities of one or more orders of magnitude.

As shown in Figure 3e, the spatial resolution of the input CORINE Land Cover data has direct implications on the accuracy of the feasibility map, and higher resolution data are being considered to improve our maps in the future.

\section{CONCLUSIONS}

Our study shows the potential of InSAR monitoring of geohazards in Great Britain with ERS-1/2 and ENVISAT imagery archives, but also data from the forthcoming Sentinel-1 constellation that will provide unprecedented and long-term SAR observations of the Earth's surface starting at the beginning of 2014 .

Based on the results of our analyses over the entire landmass, we identified several landsliding areas where the feasibility maps show significant potential for SAR-based studies of landslide ground motions over the past two decades. We will undertake advanced processing techniques at selected test sites including the South Wales Coalfield and The Pennines; landslides affecting transport infrastructure in Folkestone Warren, and Broken Bank; and coastal sites in the Isle of Wight and Cayton Bay.

ERS-1/2 and ENVISAT InSAR monitoring in 19922010 over these regions will support BGS/NERC landslide research currently carried out by using both traditional and new mapping technologies, including digital stereoscopic aerial photo interpretation, digital field data capture, terrestrial LiDAR, and differential GPS. This analysis is being supported by the ESA Category-1 project id.13543, 'Enhancing landslide research and monitoring capability in Great Britain using C-band satellite SAR imagery and change detection, InSAR and Persistent Scatterers techniques', and its results are being used to validate the feasibility maps generated during the first stage of the project. 

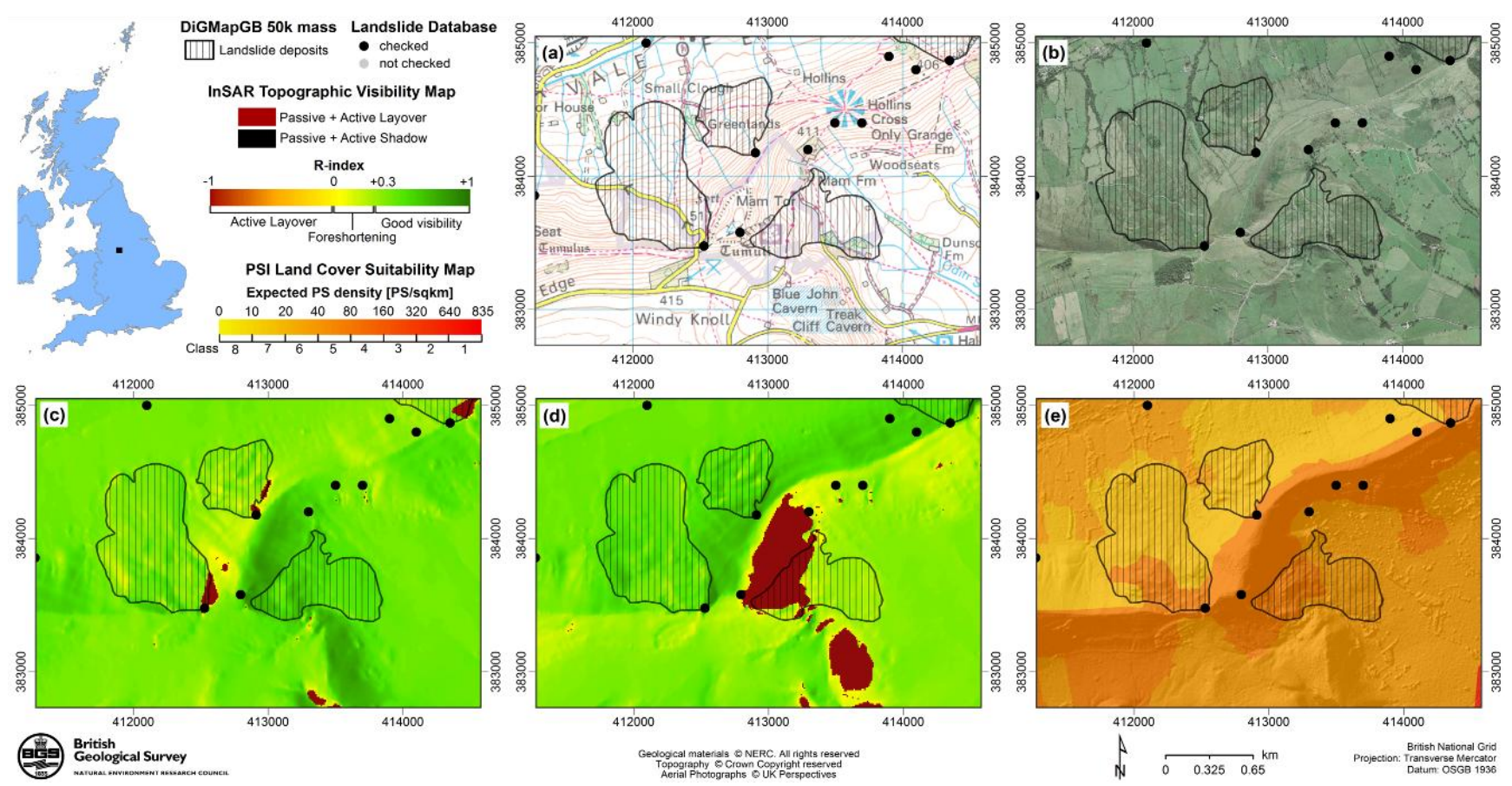

Figure 3: BGS DiGMapGB-50k mass movement layer (landslide deposits) and National Landslide Database for the area of Mam Tor, Derbyshire, overlapped onto: (a) OS 1:50,000 topographic base map, (b) $25 \mathrm{~cm}$ aerial photographs, (c-d) InSAR topographic visibility maps to the ERS-1/2 and ENVISAT acquisition geometry in ascending $(c)$ and descending $(d)$ mode based on 10m NextMap DTM, and (e) expected target densities from the calibrated CORINE Land Cover 2006 map overlaying 50m NextMap DTM hillshade.

\section{ACKNOWLEDGEMENTS}

This paper is published with the permission of the Executive Director of the British Geological Survey (BGS-NERC). Input PSI data were made available via the ESA Terrafirma and EC FP7 PanGeo projects.

\section{REFERENCES}

[1] D. Massonnet, and K.L. Feigl, "Radar interferometry and its application to changes in the Earth's surface", Reviews of Geophysics, 36(4), 441-500, 1998.

[2] Bally, Ph., Scientific and Technical Memorandum of The International Forum on Satellite EO and Geohazards, Santorini, Greece, 21-23 May 2012, GEO-ESA Report, ESA/ESRIN, 2012.

[3] P. Farina, D. Colombo, A. Fumagalli, F. Marks, and S. Moretti, "Permanent Scatterers for landslide investigations: outcomes from the ESA-SLAM project”, Eng. Geol., 88, pp. 200-217, 2006.

[4] DO-SMS, SUDOE Interreg IV B: http://dosms.get.obs-mip.fr

[5] ESA GMES Terrafirma: http://www.terrafirma.eu.com

[6] EC FP7 SAFER: http://www.emergencyresponse.eu

[7] EC FP7 DORIS: http://www.doris-project.eu

[8] G. Herrera, D. Notti, J.C. García-Davalillo, O. Mora, G. Cooksley, M. Sánchez, A. Arnaud, and M. Crosetto, "Analysis with C- and X-band satellite SAR data of the Portalet landslide area", Landslides, 8, pp. 195-206, 2011.

[9] F. Cigna, S. Bianchini, and N. Casagli, "How to assess landslide activity and intensity with Persistent Scatterer Interferometry (PSI): the PSI-based matrix approach", Landslides, pp. 1-17, doi: 10.1007/s10346-012-0335-7, in press.

[10] F. Cigna, L. Bateson, C. Jordan, and C. Dashwood, "Feasibility of InSAR technologies for nationwide monitoring of geohazards in Great Britain", Proc. RSPSoc Annual Conference 2012, 12-14 Sept. 2012, Greenwich, UK, 2012.

[11] W. Kropatsch, and D. Strobl, "The generation of SAR layover and shadow maps from Digital Elevation Models", IEEE Trans. Geosc. Remote Sensing, 28, pp. 98-106, 1990.

[12] D. Notti, J.C. Davalillo, G. Herrera, and O. Mora, "Assessment of the performance of X-band satellite radar data for landslide mapping and monitoring: Upper Tena Valley case study", Nat. Hazards Earth Syst. Sci., 10, pp. 1865-1875, 2010.

[13] European Environment Agency report, "CORINE land cover part 1: methodology", 1994.

http://www.eea.europa.eu/publications/COR0-part1

[14] A. Sowter, L. Bateson, P. Strange, K. Ambrose, and M. Syafiudin, "DInSAR estimation of land motion using intermittent coherence with application to the South Derbyshire and Leicestershire coalfield", Geophys. Res. Lett., in press. 